\title{
Networks to strengthen community social capital for suicide prevention in regional Australia: The LifeSpan Suicide Prevention Initiative
}

Janet C. Long

Australian Institute of Health Innovation

Colum Ruane

Australian Institute of Health Innovation

Louise A. Ellis

Australian Institute of Health Innovation

Rebecca Lake

The Australian Institute of Health Innovation

Anneke Le Roux

The Australian Institute of Health Innovation

\section{Luke Testa}

The Australian Institute of Health Innovation

\section{Fiona Shand}

The Black Dog Institute

\section{Michelle Torok}

The Black Dog Institute

Yvonne Zurynski ( $\square$ yvonne.zurynski@mq.edu.au )

Macquarie University https://orcid.org/0000-0001-7744-8717

\section{Research}

Keywords: Social network analysis, suicide prevention, social capital, implementation strategies

Posted Date: January 4th, 2021

DOl: https://doi.org/10.21203/rs.3.rs-136813/v1

License: (1) (i) This work is licensed under a Creative Commons Attribution 4.0 International License. Read Full License 
Page $2 / 23$ 


\section{Abstract}

\section{Background}

LifeSpan is a recently implemented suicide prevention initiative developed by the Black Dog Institute that draws upon nine evidence-based community-wide prevention strategies. We examined how the implementation of LifeSpan used the strategy of forming a suicide prevention Collaborative group (The Collaborative) at each site. We evaluated how this had affected the social capital of the community and the effectiveness of the group through the growth of the key stakeholders' socio-professional network.

Methods

This was a mixed methods study. Participants were The Collaborative and working group members at four sites implementing the LifeSpan initiative in New South Wales. Quantitative social network data was collected through an online survey and qualitative data through focus groups with The Collaborative members and interviews with LifeSpan Coordinators.

Results

There was clear quantitative evidence of increased engagement across key stakeholders in the region, who were not previously working together. This extended beyond the formal structure of The Collaborative. LifeSpan Coordinators were empirically identified as key players in the networks. Benefits of this collaborative approach included greater capacity to run activities, better communication between groups, identification of "who's who" locally, improvement in the integration of priorities, services and activities, and personal support for previously isolated members.

It was noted that the LifeSpan Coordinators were key to the smooth running of The Collaborative and its resulting combined effort, but this may represent a risk to its sustainability if they left. The model of collaboration that suited metropolitan sites was seen as difficult to sustain in one rural site but gains at this site were seen in better coordinated postvention efforts. Engagement was difficult with some clinically based services at some sites.

Conclusion

LifeSpan Coordinators were noted to be exceptional people that magnified the benefits of collaboration. Geographic proximity was also seen as a potent driver of social capital. Initial engagement with local stakeholders was seen as essential but time consuming (and "invisible") work in the implementation phase.

\section{Contribution To The Literature}

- The positive influence of social capital within communities is well known. This study unpicks the process and outcomes of a program that builds the capacity and integration of services within local 
communities.

- For implementation projects targeting low incidence, high impact issues (here death by suicide), alternative socially-based measures can be used to evaluate outcomes.

- Social network analysis is used to empirically measure this growth in collaboration across mental health, health, government and non-government sectors.

\section{Background}

Social capital is famously defined as the "value in social networks"(1). Networks provide social support, a sense of belonging, and allow access to practical assistance, resources, expertise, and experience. Social capital arising from the local community is recognised as having a positive influence on mental health (2). Collaborative community networks or partnerships have long been recognised as valuable ways to address public health issues linking formal services and informal groups with a common interest or goal.

Community networks aim to change two separate but related factors. Firstly, they aim to change the community context in which health behaviours of individuals are grounded. By changing the context and harnessing positive factors within the community (e.g., a sense of belonging and inclusion, providing access to practical support) improvements in health outcomes can be achieved (3). Secondly, collaborative community networks seek to improve health outcomes through interventional programs. Collaboration between local service agencies focusses action by clarifying the vision or agenda of the community, allows access to varied expertise, experience and resources, and can greatly enhance the reach of the program through the larger cumulative network of collaborative members (4).

The Black Dog Institute (BDI), a medical research institute focussed on all aspects of mental health, developed LifeSpan as a new evidence-based approach to suicide prevention, grounded in the community and harnessing lived experience $(5,6)$. LifeSpan combines nine different strategies into one program and the delivery of these strategies is managed at each implementation site by LifeSpan Coordinators in collaboration with the LifeSpan central team at BDI. The nine strategies are: 1) improving emergency and follow up care for those in suicidal crisis; 2) using evidence-based treatments; better equipping primary care to identify and support people in distress; improving the competency and confidence of frontline workers to deal with suicidal crisis; partnering with schools to promote help-seeking, mental health and resilience; engaging the community and providing opportunities to be part of the change; training the community to recognise and respond to suicidality; encouraging safe and purposeful media reporting; and improving safety and reducing access to means of suicide (7). Given these multiple strands within the program, robust collaboration, referral and communication networks between the LifeSpan project staff and all stakeholders in the community and in the health system, are paramount.

Recognising that social capital is a known facilitator of whole of community programs (2), BDI considered it important to develop a robust collaboration and referral network among the different strands of LifeSpan, to link up resources and expertise, and to ensure clear, cohesive communication throughout each site's region (7). If not already established, each site was required to form a central group 
as part of their expression of interest to the BDI. LifeSpan Coordinators set engagement with this group and wider community engagement with local mental health services and other agencies and groups working in the suicide prevention field (e.g., local councils, non-government organisations, workplaces, schools) as a high priority. In this study, we consider changes around community social capital and connection of different local groups over time, as related to the LifeSpan program, to deal with the challenge of suicide prevention.

Social network research is a unique methodology that allows visualisation and quantification of the social context of a setting $(8,9)$ by mapping the extent and nature of relationships between members of a defined group. Relationships such as initiating collaborative partnerships, seeking advice, or learning complex new processes through mentorship are examples (10-14). Sociograms and network parameters such as density can diagnose strengths of the group, and risks to the efficient operation of the network, and suggest specific interventions to strengthen network function (8). Longitudinal data can be used to track growth or decay of ties and the effect of interventions. We hypothesised that sociograms, illustrating the links between key community stakeholders before and after the LifeSpan initiative would provide empirical evidence of the effect of this community strategy by showing the growth of collaboration between people working at each site in the suicide prevention field.

The aims of this study were to assess the existing networks between groups working in the suicide prevention space at baseline in each site (before the LifeSpan project started) and then to assess how these networks changed as a result of the implementation of LifeSpan. The results of this study provide useful information not only in the context of LifeSpan, but for other similar community-based multilevel suicide prevention approaches.

\section{Methods}

Design

We used a mixed methods design for this study: quantitative data from an online social network survey, and qualitative data from a series of focus groups and interviews held at each of the four sites. Ethical approval for the study was granted by the Hunter New England Human Research Ethics Committee (2019/ETH03862).

\section{Setting}

LifeSpan was implemented at four sites which were selected from an expression of interest process across regional and rural New South Wales, Australia. We refer to the sites by pseudonyms: Sites Alpha, Beta, Gamma and Delta. The current study was part of a larger implementation evaluation of the LifeSpan program. The model for implementation was similar but unique at each site with the Coordinators coming under the governance of either the Local Health District (LHD), the Primary Health Network (PHN) or both. Three of the key activities that were undertaken at all sites were Youth Aware Mental Health (YAM) in secondary schools, Question, Persuade, Refer (QPR) training on how to talk about 
mental health with colleagues or friends in the broader community, and local mental health services engagement. Table 1 provides basic information about each site.

Table 1

Description of the four sites (LHD = Local Health District; PHN = Primary Health Network)

\begin{tabular}{|lllll|}
\hline Site & Hosted by & Setting & Interviews* & $\begin{array}{l}\text { Number of Focus Groups } \\
\text { (participants) }\end{array}$ \\
\hline Site Alpha & LHD & $\begin{array}{l}\text { Metro / } \\
\text { Regional }\end{array}$ & 3 & $1(5)$ \\
\hline Site Beta & $\begin{array}{l}\text { PHN \& } \\
\text { LHD }\end{array}$ & $\begin{array}{l}\text { Metro / } \\
\text { Regional }\end{array}$ & 3 & $3(26)$ \\
\hline $\begin{array}{l}\text { Site } \\
\text { Gamma }\end{array}$ & LHD & $\begin{array}{l}\text { Metro / } \\
\text { Regional }\end{array}$ & $4^{*}$ & $1(10)$ \\
\hline Site Delta & PHN & Regional / Rural & $6 *$ & n/a \\
\hline
\end{tabular}

At each site the LifeSpan Coordinators worked with the central collaborative group and convened a number of smaller working groups as part of the implementation process of Lifespan in their area. This was done differently at each site, although all sites utilised the existing mental health collaborations. The central collaborative group was referred to by different names at each site, e.g., "the Alliance." We have standardised the terminology to "The Collaborative" across all sites (which includes the various associated LifeSpan working groups) for clarity in the reporting of our results.

LifeSpan was delivered via a stepped wedge design where sites were randomised to a staggered start date. The research team first engaged each site in July of 2019 in the final year of active implementation of the LifeSpan model. Two sites had completed active implementation at this point. Initial contact sought to establish cordial relations with site coordinators and establish a plan for evaluation activities going forward. All personnel across each respective site were made aware of an external evaluation of the implementation of the Lifespan program.

Quantitative data collection: social network study

Data was collected through an online survey, which asked respondents about their socio-professional networks, prior to, and following, the implementation of LifeSpan in their area. All members of The Collaborative and/or working groups formed at three of the four sites (Alpha, Beta and Gamma) as well as their respective LifeSpan Coordinators, were identified and invited to participate. The survey was deemed inappropriate at Site Delta at that time due to a number of local issues (including lack of capacity to attend meetings, recent catastrophic bushfires, and COVID-19 response).

Individual surveys at each site were administered at least 12 months after LifeSpan activities had commenced to allow time for the network to be initiated. Potential participants were invited via an email 
containing survey information and a secure link. Where possible, the survey was completed at the end of focus groups or interviews to smooth the data collection process and minimise disruption for staff and stakeholders. A paper Participant Information form was made available for this purpose. All participants were required to provide consent on the landing page of the survey before progressing to the questions. The online survey platform used was Qualtrics (15). Participants who accidently completed the survey twice were identified and duplicate data removed.

Respondents were presented with a list of people identified as LifeSpan Collaborative or working group members (see Supplementary File A for survey questions). For each name provided, respondents were asked if they were collaborating with the person, had made the collaborative link as a result of LifeSpan or whether it was a pre-existing link, and to specify the nature of the link (referral, shared care of a client, working in other ways). While names were used on the survey to reliably identify contacts and allow aggregation of data across respondents, once submitted, data were coded, and names were removed.

\section{Social network analysis}

Social network data was analysed using UCInet v.6(16) and diagrams of the relationships were constructed using Gephi 0.9.2 software (17). Network parameters of density, centrality and brokerage were computed. Social network parameters and definitions are shown in Table 2.

Table 2

Social network parameters and their definitions

\begin{tabular}{|ll|}
\hline Term & Definition \\
\hline Node & Each node represents a member of the network \\
\hline Tie & A tie represents a self-reported link between two nodes \\
\hline Density & $\begin{array}{l}\text { The number of actual ties divided by the number of possible ties. Reported as a } \\
\text { percentage }\end{array}$ \\
\hline Degree & $\begin{array}{l}\text { Number of ties per node (either nominated by others or by the member } \\
\text { themselves) }\end{array}$ \\
\hline Indegree & Number of ties reported by others directed to the focal member \\
\hline Centrality & Members with the highest interaction (ties to and from) with others \\
\hline $\begin{array}{l}\text { Betweenness } \\
\text { centrality }\end{array}$ & $\begin{array}{l}\text { Members who have high brokerage potential as they link two nodes that are not } \\
\text { otherwise linked. }\end{array}$ \\
\hline
\end{tabular}

Qualitative data collection: interviews and focus groups

Qualitative data were collected through semi-structured interviews and focus groups at each site involving multiple stakeholders engaged in the implementation process in various organisational and community level positions. The researchers scheduled interviews with LifeSpan Coordinators at each site and aligned focus groups to coincide with regular collaborative meetings, to maximise participation. Key 
personnel involved in Lifespan activities locally were identified for interview in consultation with the LifeSpan team at BDI and the local LifeSpan Coordinators. All individuals received a consent form and information sheet outlining the nature of the research and the anonymity of their responses. Focus groups were conducted face to face while interviews were undertaken either in person or via Zoom, depending on availability. All interviews and focus groups were conducted by senior health services researchers experienced in qualitative research $(Y Z, J L, L E)$ and were audio recorded and transcribed verbatim.

Drawing on the Consolidated Framework of Implementation Research (CFIR)(18), an interview guide was developed in which questions acted as prompts allowing for the development of relevant issues as they emerged in both the face-to-face interviews and focus groups conversations (19). Questions explored the fidelity of LifeSpan in each region, the barriers and enablers to implementation, insights to key roles associated with implementation, and how existing and new networks and/or relationships facilitated the delivery of Lifespan.

Qualitative analysis

All interview and focus group data were transcribed and imported in NVivo 12 for analysis (20). Data analysis followed a thematic deductive approach utilising the CFIR as an analytical framework with inductive insights added as the coding process evolved. The CFIR is a comprehensive meta-theoretical framework that provides a taxonomy of standardised operationally defined constructs to guide systematic assessment in the identification of factors influencing implementation of complex programs within complex contexts (18). A key construct within this study was in the Inner Setting Domain: 'Networks and Communications'. This construct facilitated description of the nature, quality, and evolution of organisational networks within the inner context. The Inner Setting was defined with respect to the organisational variables and factors that had direct influence on and involvement in Lifespan implementation at each site.

The analytic work was an iterative process and was performed side by side with the data collection due to the time between conducting interviews. This allowed for the outcomes of initial coding to be fed back into subsequent interview analysis. A three-step process for coding the interview and focus group data was utilised to ensure intercoder reliability (21). The initial stage involved researchers (JL, CR, LE \& YZ) using the CFIR to independently code an interview transcript. This coding along with inductive insights that opened up other avenues of interest was then compared for reliability among the research team and any inconsistencies were discussed and agreed upon. This led to a high degree of intercoder reliability among the research team (22). The final stage involved the coding of the remainder of the transcripts utilising the CFIR and following agreed upon inductive insights. Frequent meetings continued to maintain analytic rigour. Supplementary File B shows the COnsolidated criteria for REporting Qualitative research (COREQ) checklist for qualitative research (23).

\section{Results}




\section{Demographics}

The response rate for the three site surveys ranged between $15 \%$ and $67 \%$, (Table 3). At each site, we were confident that data from the key network players had been captured (justifying the seemingly low response rates). All respondents gave consent on the landing page.

Table 3

Survey responses by site

\begin{tabular}{|llll|}
\hline & Invited ( $\mathbf{n})$ & Respondents (n) & Response rate (\%) \\
\hline Site Alpha & 103 & 26 & $25 \%$ \\
\hline Site Beta & 70 & 46 & $67 \%$ \\
\hline Site Gamma & 75 & 11 & $15 \%$ \\
\hline
\end{tabular}

\section{Roles of respondents}

Respondents were asked to select their role from a list of ten options. Selection of multiple roles was possible. The categories were: leadership, mental health clinician, YAM facilitator or helper, community champion, person with lived experience (community advocate), suicide prevention team, involved in postvention, priority population representative, and other. Roles added under the 'other' category included: Mental Health First Aid Officer, trainer, paramedic, and drug and alcohol worker. Most frequent response at Site Beta and Gamma was "I provide leadership," and at Site Alpha, "Suicide prevention team." Results are summarised in Fig. 1.

\section{Network Diagrams}

Three network diagrams are shown for each of the sites: Alpha, Beta and Gamma in Figs. 2-4. The first shows existing ties from before LifeSpan, the second, new ties that came about through LifeSpan, and the third shows all ties at the time of the survey. Respondents at each site numbered 26, 46 and 11 (at Sites Alpha, Beta and Gamma respectively). Each respondent nominated an average of 5.2, 4.9 and 3.3 ties, which included people from outside our list of identified members. The number of new ties at each site made up $71 \%, 70 \%$ and $47 \%$ of the total ties, (Table 4). People who were nominated the most (highest centrality) at each of the sites were the LifeSpan Coordinators. People with the highest brokerage potential (connecting two other people by the shortest path) tended to be people in executive / senior management or coordination roles of larger services; for example, local PHN, Aboriginal Health Service, LHD, or Lived Experience Group. 
Table 4

Characteristics of the social networks of the three sites.

\begin{tabular}{|llll|}
\hline Network metric & $\begin{array}{l}\text { Site } \\
\text { Alpha }\end{array}$ & $\begin{array}{l}\text { Site } \\
\text { Beta }\end{array}$ & $\begin{array}{l}\text { Site } \\
\text { Gamma }\end{array}$ \\
\hline Density of collaboration network & 0.05 & 0.10 & 0.10 \\
\hline Number of respondents reporting their ties & 26 & 46 & 12 \\
\hline Number of people shown in the network & 107 & 61 & 85 \\
\hline Number of ties reported (total) & 536 & 438 & 108 \\
\hline Number of new ties to people they did not know pre-network (\%) & 380 & 307 & $51(47 \%)$ \\
\hline $\begin{array}{l}\text { Number of people nominated from outside our list of identified } \\
\text { collaborators }\end{array}$ & 4 & 4 & 10 \\
\hline Average degree & 5.2 & 4.9 & 3.3 \\
\hline
\end{tabular}

Qualitative data

A total of 53 individuals responded to our invitation and participated in interviews and focus groups across the four sites. Eighteen interviews, some of which were in group format (2-3 people) due to time constraints, and five focus groups were conducted across all four sites (See Table 1). Interviews and focus groups mostly took place at the end of a scheduled LifeSpan Collaborative meeting, or via Zoom. Interviews and focus groups lasted around an hour.

Eleven subthemes that illustrate the CFIR concept "networks and communications" at the sites were identified from the interview and focus group data and are shown with exemplary quotes in Table 5 (see end of text). Roman numerals below refer to relevant quotes in Table 5 (e.g., Table 5: ii). 
Table 5

Exemplary quotes from the focus groups and interviews undertaken with stakeholders involved with LifeSpan.

\begin{tabular}{|c|c|c|c|}
\hline & Theme/issue & Exemplar quote & Source \\
\hline \multirow[t]{5}{*}{$\mathrm{i}$} & \multirow{5}{*}{$\begin{array}{l}\text { Value of the } \\
\text { Collaborative } \\
\text { approach }\end{array}$} & $\begin{array}{l}\text { Facilitator: What do you think have been the key lessons that } \\
\text { have come out of this part of the [LifeSpan] project? }\end{array}$ & \multirow[t]{2}{*}{$\begin{array}{l}\text { Site Beta FG } \\
\# 1[\mathrm{LHD}]\end{array}$} \\
\hline & & $\begin{array}{l}\text { [LHD member]: I'd say having [a Collaborative] is central to } \\
\text { achieving new goals... I think I'd have to own that when } \\
\text { [LifeSpan Coordinators ] said that they were going to } \\
\text { approach the Chamber of Commerce and do some work with } \\
\text { them, I thought here we go. This is a bit out there! But } \\
\text { actually, it has been really valuable. That's put a lot of people } \\
\text { into the QPR [Question, Persuade, Refer] process. }\end{array}$ & \\
\hline & & $\begin{array}{l}\text { Facilitator: What are the key lessons from [Site Alpha] that } \\
\text { you would tell new sites about? }\end{array}$ & \multirow{2}{*}{$\begin{array}{l}\text { Site Alpha } \\
\text { FG\#3 } \\
\text { [Priority } \\
\text { Population } \\
\text { health } \\
\text { professional } \\
\text { 1] }\end{array}$} \\
\hline & & $\begin{array}{l}\text { [Priority Population health professional] I think definitely use } \\
\text { the round table type [approach] ... come together. I think that } \\
\text { is really positive. }\end{array}$ & \\
\hline & & $\begin{array}{l}\text { I think the value [of the Collaborative group] was } \\
\text { acknowledged; that there was a big hole in this area. And this } \\
\text { was only the beginning of the process. Trying to get people } \\
\text { together and talking and seeing what we could offer. }\end{array}$ & $\begin{array}{l}\text { Site Beta FG } \\
\# 1 \text { [Police] }\end{array}$ \\
\hline ii & $\begin{array}{l}\text { Inviting people } \\
\text { to join the } \\
\text { LifeSpan } \\
\text { Collaborative } \\
\text { was labour } \\
\text { intensive at } \\
\text { some sites }\end{array}$ & $\begin{array}{l}\text { I did feel like I was spending a lot of time having coffees and } \\
\text { talking to people and not a lot of time 'working'. }\end{array}$ & $\begin{array}{l}\text { Site Delta } \\
\text { FG\#1 } \\
\text { [LifeSpan } \\
\text { Coordinator } \\
\text { A] }\end{array}$ \\
\hline \multirow[t]{2}{*}{ iii } & \multirow[t]{2}{*}{$\begin{array}{l}\text { LifeSpan is } \\
\text { the "anchor" or } \\
\text { "glue" of the } \\
\text { community } \\
\text { effort }\end{array}$} & $\begin{array}{l}\text { [LifeSpan coordinator] would attend all of those groups. I } \\
\text { think they were sort of the one anchor that, they kept, even } \\
\text { though we were autonomous and we were allowed to } \\
\text { develop some stuff by ourselves, they kept us focused, even } \\
\text { though we were also looking at what was happening more } \\
\text { locally, on the ground for ourselves, you know. }\end{array}$ & $\begin{array}{l}\text { Site Alpha } \\
\text { FG\#3 } \\
\text { [Priority } \\
\text { Population } \\
\text { health } \\
\text { professional } \\
1]\end{array}$ \\
\hline & & $\begin{array}{l}\text { But you can see how this [Collaborative group] kind of held a } \\
\text { lot - no matter what happened, we were here together, } \\
\text { working on it, trying to make the best of the situation, } \\
\text { whether it was good, bad or whatever. So, you know, we are } \\
\text { grateful to LifeSpan for helping be that glue. }\end{array}$ & $\begin{array}{l}\text { Site Gamma } \\
\text { FG\#1 [LHD] }\end{array}$ \\
\hline
\end{tabular}

(Abbreviations: LHD = Local Health District, PHN = Primary Health Network, FG = Focus Group) 


\begin{tabular}{|c|c|c|c|}
\hline & Theme/issue & Exemplar quote & Source \\
\hline iv & $\begin{array}{l}\text { Value of a } \\
\text { community } \\
\text { approach to } \\
\text { activities }\end{array}$ & $\begin{array}{l}\text { Going back a number of years, there was a lot of activity } \\
\text { [after a death by suicide], but it really lacked that } \\
\text { coordination. I don't think anyone was taking responsibility } \\
\text { for identification of when there's been a death, who needs to } \\
\text { be involved in that response, is there someone already } \\
\text { involved? }\end{array}$ & $\begin{array}{l}\text { Site Delta } \\
\text { [PHN] }\end{array}$ \\
\hline v & $\begin{array}{l}\text { Value of } \\
\text { support within } \\
\text { the } \\
\text { Collaborative }\end{array}$ & $\begin{array}{l}\text { Certainly, from our perspective, we just see too much of it } \\
\text { [death by suicide] every day. We had one yesterday, with one } \\
\text { of our ex colleagues. Yeah, there really has been a lack in } \\
\text { support for families as well as the individuals. So, to get all } \\
\text { the players together to a one stop shop is a great idea. And } \\
\text { it's the starting point. It's not the end point. You can only keep } \\
\text { going from there. }\end{array}$ & $\begin{array}{l}\text { Site Beta FG } \\
\# 1 \text { [Police] }\end{array}$ \\
\hline vi & $\begin{array}{l}\text { Achieving and } \\
\text { maintaining } \\
\text { buy-in }\end{array}$ & $\begin{array}{l}\text { I sit on the executive [of the Collaborative group] and we } \\
\text { want everybody in the [group] to have buy-in. However, you're } \\
\text { right, at the executive level, we do talk about things and we } \\
\text { say 'okay, well we've made the decision, but that's not final. } \\
\text { Now we need to take it back to the group today.' And so yeah, } \\
\text { it does take that little bit longer, but it has that impact of } \\
\text { everyone has that buy-in. ... By definition, it is a Collaborative. } \\
\text { It is astonishing in my view to see how much work and the } \\
\text { goodwill that gets done under that. }\end{array}$ & $\begin{array}{l}\text { Site Alpha } \\
\text { FG\#3 } \\
\text { [LifeLine] }\end{array}$ \\
\hline \multirow[t]{2}{*}{ vii } & $\begin{array}{l}\text { Linking people } \\
\text { to } \\
\text { resources/help }\end{array}$ & $\begin{array}{l}\text { Setting up the website, all those kinds of things that we're } \\
\text { linking people in the community it's probably been one of the } \\
\text { most valuable and particularly in engaging businesses... } \\
\text { That's the feedback I keep getting when I travel around is } \\
\text { people in businesses saying that we didn't know; or we are } \\
\text { still finding businesses that are saying where do we go to get } \\
\text { help? And we can direct them to that help. }\end{array}$ & $\begin{array}{l}\text { Site Beta } \\
\text { FG\#1 } \\
\text { [LifeSpan } \\
\text { Coordinator] }\end{array}$ \\
\hline & & $\begin{array}{l}\text { It is good to know that the players, like getting a group } \\
\text { together who actually know the individual players in each } \\
\text { area to speak over issues or put people in touch with } \\
\text { individuals. }\end{array}$ & $\begin{array}{l}\text { Site Beta FG } \\
\# 1 \text { [Police] }\end{array}$ \\
\hline viii & Flat hierarchy & $\begin{array}{l}\text { I find that the networking aspects of [the Collaborative] is } \\
\text { really important. And I love the way that usually that } \\
\text { leadership, I love the way that anyone can be invited to } \\
\text { champion this cause regardless of whether you're in a high } \\
\text { level, executive position, or, you know, if you're just a regular } \\
\text { person. }\end{array}$ & $\begin{array}{l}\text { Site Alpha } \\
\text { Focus } \\
\text { Group \#1 } \\
\text { [Priority } \\
\text { population } \\
\text { Health } \\
\text { professional } \\
\text { 2] }\end{array}$ \\
\hline ix & $\begin{array}{l}\text { Integrating } \\
\text { care; aligning } \\
\text { of objectives }\end{array}$ & $\begin{array}{l}\text { How does health and the PHN work together? I think that is } \\
\text { an important component of it. I think that has been really } \\
\text { helpful having [LHD member] and then now [PHN member] } \\
\text { on board. But before that we were kind of playing catch up } \\
\text { all the time between the two services about where we were } \\
\text { going, and the idea of stepped care and all those things. }\end{array}$ & $\begin{array}{l}\text { Site Beta FG } \\
{[\mathrm{PHN}]}\end{array}$ \\
\hline
\end{tabular}

(Abbreviations: LHD = Local Health District, PHN = Primary Health Network, FG = Focus Group) 


\begin{tabular}{|c|c|c|c|}
\hline & Theme/issue & Exemplar quote & Source \\
\hline$x$ & $\begin{array}{l}\text { "Mapping" of } \\
\text { key services }\end{array}$ & $\begin{array}{l}\text { What I've noticed is that people wanted to do something, and } \\
\text { that it's disparate. When I first started, there were disparate } \\
\text { groups all over the place, not coming together. And } \\
\text { saying: "Well, we do that bit" "Oh, I never knew you did that. } \\
\text { Oh, I thought you did this", "No, no, we don't do that." And } \\
\text { then you are finding out, it's basically a bit of a mapping of } \\
\text { who are the key movers and shakers in our region? Who's } \\
\text { actually doing prevention, early Intervention, critical } \\
\text { intervention and postvention. And we're getting that clearer } \\
\text { now with the [Collaborative] members. }\end{array}$ & $\begin{array}{l}\text { Site Beta } \\
\text { Interview } \\
\text { [LifeSpan } \\
\text { Coordinator] }\end{array}$ \\
\hline \multirow[t]{2}{*}{ xi } & $\begin{array}{l}\text { Success } \\
\text { dependent on } \\
\text { geography to } \\
\text { some extent }\end{array}$ & $\begin{array}{l}\text { The way that we set up our [Collaborative] was based off a } \\
\text { metro model and has never really gotten the same traction as } \\
\text { the metro [Collaboratives] ..., but in saying that, we've had } \\
\text { some individuals or working groups that have helped } \\
\text { implement those strategies anyway, but the one big meeting } \\
\text { to share knowledge and, you know, implement things just } \\
\text { never worked. }\end{array}$ & $\begin{array}{l}\text { Site Delta } \\
\text { FG\#1 } \\
\text { [LifeSpan } \\
\text { Coordinator } \\
\text { A] }\end{array}$ \\
\hline & & $\begin{array}{l}\text { It's one of the advantages of not being a group of suburbs. } \\
\text { That this is a town and people know each other in [Site } \\
\text { Gamma]. Everybody's got a connection to somebody, } \\
\text { somewhere and if you need or want anything, someone will } \\
\text { know who to talk to. }\end{array}$ & $\begin{array}{l}\text { Site Gamma } \\
\text { FG\#1 [LHD } \\
\text { 2] }\end{array}$ \\
\hline \multirow[t]{2}{*}{ xii } & $\begin{array}{l}\text { Building on } \\
\text { existing } \\
\text { Collaborative } \\
\text { relationships }\end{array}$ & $\begin{array}{l}\text { I think we had really good local leadership and commitment } \\
\text { [at the start of the LifeSpan project], as evidenced by all the } \\
\text { people who came to the table regularly. And that was really } \\
\text { built on a bedrock of good work that's been done in this area } \\
\text { for a long time. So, it wasn't like we were manufacturing it } \\
\text { out of nothing. }\end{array}$ & $\begin{array}{l}\text { Site Gamma } \\
\text { FG\#1 [LHD } \\
1]\end{array}$ \\
\hline & & $\begin{array}{l}\text { There's a sense of community spirit [in Site Gamma]. I can } \\
\text { see it. I've been here } 12 \text { years. I can see it amongst families } \\
\text { and communities... you can see that basic social connection. } \\
\text { Local intel, isn't it? }\end{array}$ & $\begin{array}{l}\text { Site Gamma } \\
\text { FG\#1 [LHD } \\
2\end{array}$ \\
\hline xiii & $\begin{array}{l}\text { LifeSpan } \\
\text { Coordinators' } \\
\text { role in building } \\
\text { social capital }\end{array}$ & $\begin{array}{l}\text { One of my standout things around [the LifeSpan } \\
\text { Coordinators] aside from the support that they give us, it's } \\
\text { their genuine, and I really mean that, belief in what people } \\
\text { with a lived experience can offer... sitting around a table with } \\
\text { people who might have degrees as long as their arms and } \\
\text { are called doctors and the CEOs. And to know that what you } \\
\text { have to say, is just as important to them, as what they have } \\
\text { to say is important to us, that is a big, big plus. }\end{array}$ & $\begin{array}{l}\text { SiteW_FG\#2 } \\
\text { [Person with } \\
\text { lived } \\
\text { experience] }\end{array}$ \\
\hline
\end{tabular}

(Abbreviations: LHD = Local Health District, $\mathrm{PHN}=$ Primary Health Network, FG = Focus Group) 


\begin{tabular}{|c|c|c|c|}
\hline & \multirow{2}{*}{ Theme/issue } & Exemplar quote & \multirow{2}{*}{$\begin{array}{l}\text { Source } \\
\text { Site Alpha } \\
\text { FG\#3 } \\
\text { [Priority } \\
\text { population } \\
\text { health } \\
\text { professional } \\
\text { 1] }\end{array}$} \\
\hline & & $\begin{array}{l}\text { I actually started ... having a bit of a vent, and I actually did } \\
\text { get quite emotional, as I do. And you know, they rang me and } \\
\text { [LifeSpan Coordinator] was like 'are you okay?' and so that } \\
\text { checking in stuff as well. So, you know, we're not just } \\
\text { collaborative members, we are people and we are, you know, } \\
\text { we feel pain and sadness and tiredness all that sort of stuff, } \\
\text { and I think, yeah, [the LifeSpan Coordinators] have really, it's } \\
\text { still personal, and they still treat us like people and that's } \\
\text { lovely sometimes when you see, you know, collaborative } \\
\text { members around town or you know at council or wherever } \\
\text { you are different places and everyone was like, 'Oh how are } \\
\text { you going?' you know, so yeah, again I think it's more than } \\
\text { collaborative, it's friendships, it's relationships and I think } \\
\text { that's the thing isn't it, it's that relationship. }\end{array}$ & \\
\hline xiv & $\begin{array}{l}\text { LifeSpan } \\
\text { Coordinators } \\
\text { seen as } \\
\text { knowledge } \\
\text { brokers }\end{array}$ & $\begin{array}{l}\text { I think the things that the coordinator role provided was - it } \\
\text { was a bit of an umbrella view of the local suicide prevention } \\
\text { work that was occurring ... Because everyone knows the bit } \\
\text { that is happening in relation to them and their organization, } \\
\text { but don't know all the other stuff. And that's really important } \\
\text {... so you don't duplicate and can share resources, you know. } \\
\text { And that's the sort of role that doesn't exist... I think it was } \\
\text { that umbrella view and being able to connect people, } \\
\text { resources and information. And so I think you have to define } \\
\text { that as acting as a bit of a knowledge broker as well. We } \\
\text { would become the people that the people would ring with } \\
\text { anything to do with suicide and suicide prevention, really, } \\
\text { anything locally - including, clinical inquiries, which we were } \\
\text { really not the people to deal with that, including being told } \\
\text { about when postvention responses were being coordinated. } \\
\text { You know we were the go to, but the role we could play in } \\
\text { that was to connect the right people, or finding out who the } \\
\text { right people were, because we had a really big network of } \\
\text { contacts. }\end{array}$ & $\begin{array}{l}\text { Site Gamma } \\
\text { Interview } \\
\text { [LifeSpan } \\
\text { Coordinator] }\end{array}$ \\
\hline
\end{tabular}

The process of forming or enhancing an existing Collaborative group to work on LifeSpan projects was discussed by all interview and focus group participants within their respective sites, usually in the context of the question "What has worked well?" All LifeSpan Coordinators noted how their initial and ongoing priority for the program was identifying, meeting with, and inviting various stakeholders to collaborate with other local community groups and services that were already working in the local suicide prevention field. This 'round table' approach was agreed as a key strategy of the LifeSpan model that contributed to success (i).

At all sites, LifeSpan Coordinators noted that this work of engagement with different stakeholders took up a considerable amount of their time, at least initially. At one site, a Coordinator described a mismatch in expectations, as the work of engaging stakeholders was largely invisible to their hosting organisation managers (ii). Adding to this work, LifeSpan Coordinators invested a lot of time in keeping groups engaged and on task. A focus group participant likened a LifeSpan Coordinator to the anchor of the 
Collaborative group maintaining focus on projects at Site Alpha, while another participant called LifeSpan Coordinators "the glue" of the Collaborative groups when things were difficult (Site Gamma) (iii).

Terms of reference and operating rules for the different versions of The Collaborative were evident across sites. However, at every site, The Collaborative was built on existing relationships and this was seen as a key success factor (xii) that provided a strong foundation to support network development. Participants discussed the benefits of linking up several groups, that were previously isolated, to do a combined event. One notable community outcome of the linking of disparate service providers in the LifeSpan Collaborative was an improvement in the suicide postvention process at Site Delta. Prior to LifeSpan, it was not always known when a death by suicide had occurred or who had already responded. First responders (ambulance / police) to a death by suicide were now starting to directly inform key members of The Collaborative who could then mobilise postvention support teams (iv).

The value of The Collaborative group in linking themselves and the stakeholders they represented into a supportive network was discussed in several focus groups. Representatives from schools, the media, police, justice, commerce, priority population advocacy groups, and people with lived experience all expressed positive outcomes from being linked via The Collaborative into training and supportive expertise. Even organisations that already had formal support and training programs appreciated the additional resources (v). Several participants noted the value of LifeSpan Coordinators as people who could direct them to the appropriate resource or answer questions (vi). LifeSpan Coordinators were also seen as enablers, being inclusive and supporting grass-roots activities (vii). It was noted at some sites that LifeSpan, or more correctly the Collaborative group brought together by LifeSpan, had brought primary health and hospital services into step, moving towards better integrated care and alignment of priorities (viii).

A common theme within the sites was that several disparate and disconnected groups were working in the suicide prevention field across each region before the implementation of LifeSpan. At Site Beta and Site Delta, the LifeSpan Coordinators spoke at length about how fragmented the local suicide prevention effort was and how there was poor understanding of individual roles and visions among them collectively (x). LifeSpan activities, where these groups were identified and engaged was seen as important in building their capacity to make change.

At the rural Site Delta, geography was discussed at length in terms of the difficulties it posed to Collaborative working and integrated effort. The Collaborative group was not as successful as they would have liked as it was "based on the metro model". The initial engagement of stakeholders in Site Delta also took longer and involved greater effort (e.g., driving for three hours one way to attend a requested face-to-face meeting) (xi).

The benefits that came from the increase in social capital were often specifically attributed to the work and qualities of the LifeSpan Coordinators who were praised for their approachability, passion, and integrity. Qualitative data collected from The Collaborative members consistently showed that the 
LifeSpan Coordinators were exceptional people who all were fully invested in their community. There was frequent praise from participants for the LifeSpan Coordinators' openness to questions, follow-up phone calls, and for their supportiveness (xiii). Reflecting on their role in the suicide prevention field in their region, one LifeSpan Coordinator used the term "knowledge broker", and explained how, because they had an "umbrella view" of all that was going on in the site they had become the go-to people to find help for problems or issues. This is reflected strongly in the quantitative social network analysis where LifeSpan Coordinators were identified as key brokers at their sites (xiv).

\section{Discussion}

The findings from this study support that the social capital of local suicide prevention agencies was strategically increased as a result of having a collaborative network in each site, and was identified as a key success factor for the implementation of LifeSpan. Our evaluation of this aspect of the program clearly shows a positive change in the social structure of the communities that implemented LifeSpan in four areas of NSW. Our quantitative, social network data from three of the sites shows how collaborative links between community stakeholders increased after 12-24 months of implementation of LifeSpan. Qualitative data from the interviews and focus groups from all sites provide insight into how this change was achieved and the benefits that this increase in social capital brought both the community and individual members of the groups.

The strategy of building local social capital was unequivocally seen as positive and a key success factor of LifeSpan. The strategy of identifying, engaging and working with a Collaborative of local individuals and groups was seen as a core strength. It was frequently acknowledged that local groups working in suicide prevention were siloed and often unaware of other activities going on. Through the Collaborative, there were opportunities to coordinate and share effort more productively.

Another manifestation of increased social capital was the effect of knowledge brokering through The Collaborative. Even for organisations with formal training or support services, knowing who to contact in The Collaborative for advice or support was highly valued by the participants. At Site Delta we heard in detail how the postvention response to a death by suicide was now improving as it was initiated and coordinated through The Collaborative network relationships.

The Collaborative and working group members covered a broad range of community and organisational stakeholders. There was representation from NSW Health (hospital, public Community Mental Health services, Drug and Alcohol Community teams), NGO mental health providers (e.g., WellWays, headspace, LifeLine), education (public schools), front-line responders (e.g., police, ambulance), people with lived experience, and priority population groups (e.g., First Nation people, LGBIQ+). At some sites extra stakeholder groups involved in suicide prevention were represented including private schools, coroners' court, media outlets, and local church support groups. While not all groups were equally invested, and there was attrition and churn of members over time, this shows the success of the engagement strategy in terms of reach. 
The most notable group that failed to respond to the call to be involved was the clinical mental health workforce working in hospitals, and community health facilities, most apparent in Site Gamma. This lack of engagement can be understood in the context of constantly high workloads, continuous change, and clashing priorities with other mental health initiatives already underway leading to "change fatigue" and lack of capacity among mental health staff (24).

A large percentage of respondents across the sites chose "I provide leadership" as their role. This was paired with a wide range of second choices such as "person with a lived experience of suicide", "YAM facilitator or helper," "mental health clinician or "involved in postvention." This confirmed that the people taking part in the Collaboratives at each site were key players in their respective areas and saw themselves as advocating and making a change on behalf of the group they represented.

The process of identifying and engaging key stakeholders at each site was described as labour intensive and often "invisible" work which almost always fell to the LifeSpan Coordinators. This was experienced despite all of the LifeSpan Coordinators (except one, at Site Delta) being local residents, embedded in these regions and often well-known in the local mental health field. This presumably would give them a head start in identifying, accessing, and engaging with key stakeholders. Building networks as a local and "one of us", rather than as an outsider, and having a known track record in the field is known to increase trust, an important precursor to engagement (25).

Different starting points contributed to the variation in scope and extent of network development across the sites. In areas where mental health services were siloed or fragmented, or where a culture of collaboration between community groups, NGO providers and NSW Health providers were limited before LifeSpan implementation, the development of functioning collaboratives was less extensive.

Although all implementation strategies and frameworks acknowledge the importance of engaging stakeholders (e.g., CFIR Process Construct (18)), the time it takes to do it effectively is likely underestimated. Some problems arose as a result of this with managers who were expecting activities to start quickly without a lengthy engagement period. Many of the LifeSpan Coordinators mentioned the value of face-to-face contact so they could learn about the person's service and role and extend a personal invitation to join the LifeSpan Collaborative. At the rural Site Delta, the preference for face-toface meetings meant that LifeSpan Coordinators would spend hours travelling to their appointments. It also meant that once the Collaborative had been established, in-person attendance at meetings were far less likely.

Site Delta did not take part in the social network survey. Although initial contact and engagement with stakeholders across the region was successful in the first period of implementation, changes in local LifeSpan personnel, and conflict with other local priorities (e.g., aftermath of catastrophic bushfires earlier in the year) meant that regional engagement with LifeSpan weakened over time. More importantly, we would argue, the vast distances between stakeholders and unstable internet service in Site Delta, meant this was not unexpected. Geographic proximity is a known driver of collaboration (26) mediated by faceto-face contact and chance local meetings (so called "corridor or car park" conversations). This supports 
the Site Delta LifeSpan Coordinator's assertion that the "metro model" does not suit a geographically dispersed site. A smaller scale version of this geographic isolation was voiced by Collaborative members from outlying towns of the other Sites.

\section{Strengths and limitations}

Social network research is uniquely placed to map the social context of a setting. While efforts were made to maximise the response rate at each site, this was not possible at Site Gamma. There are two main considerations in determining whether a whole network survey has an adequate response rate or not: the type of analysis being performed on the data (as some measures are more robust in the face of missing data than others (27)), and the suspected structure of the network. We are confident that we captured the most influential members whose high number of ties contribute most to the structure of the network (28). We have also chosen robust analytics to avoid inappropriate interpretations of the data. An integrating synthesis of quantitative data from the social network survey and qualitative data from interviews and focus groups, provides a more holistic interpretation and is a strength of the paper.

\section{Conclusions}

The LifeSpan suicide prevention program had a clear priority to identify and engage local groups and service providers to build the social capital of the intervention. All four sites showed a broad range of stakeholder groups that joined The Collaborative group and working groups. Clear benefits resulted from this: greater capacity to run activities, better communication between groups, identification of "who's who" locally, improvement in the integration of priorities, services and activities, and personal support for previously isolated members. These benefits were often specifically attributed to the LifeSpan Coordinators who were praised for their approachability, passion, and integrity. The study has also revealed the limitations of this collaborative approach in geographically dispersed regions, where the potent driver of collaboration (in-person meetings) is precluded.

\section{Abbreviations}

BDI Black Dog Institute

CFIR Consolidated Framework for Implementation Research

LGBIQ + Lesbian, gay, bisexual, intersex, queer and others

LHD Local Health District

NGO non-government organisation

NSW New South Wales

PHN Primary Health Network 
QPR Question, Persuade, Refer

SNA Social Network analysis

YAM Youth Aware Mental Health

\section{Declarations}

\section{Ethics approval and consent to participate}

Ethical approval for the study was granted by the Hunter New England Human Research Ethics Committee (2019/ETH03862). All interviewees gave written consent. Online survey respondents gave consent on the landing page of the survey.

\section{Consent for publication}

Consent as above included information about publishing results in de-identified form such that individuals and individual sites would not be recognisable.

\section{Availability of data and materials}

Data is not publicly available due to Ethics requirements that participants and sites remain unidentifiable.

\section{Competing interests}

The authors state that they have no conflicts of interest.

\section{Funding}

This study was funded by the Paul Ramsay Foundation, who fund the NSW LifeSpan trial. The funding body had no role in the conception, design, data collection, analysis or decision to publish.

\section{Authors' contributions}

Authors (YZ, LE, FS, MT and JL) designed the mixed methods implementation evaluation approach and secured funding. Authors (JL, CR, LE, LT and YZ) collected the data. Authors JL, CR, LE, YZ, RL, ALR, LT undertook the qualitative analysis. $\mathrm{JL}$ designed and analysed the social network data, generated the sociograms, drafted the manuscript. All authors reviewed and approved the final version. 


\section{Acknowledgements}

We thank the LifeSpan Coordinators and participants at each site and the Implementation team at Black Dog Institute for their openness in sharing their experience of implementation with us.

\section{References}

1. Putnam R. Bowling alone: America's declining social capital. J Democr. 1995;6(1):65-78.

2. Boyd CP, Hayes L, Wilson RL, Bearsley-Smith C. Harnessing the social capital of rural communities for youth mental health: an asset-based community development framework. Aust J Rural Health. 2008;16(4):189-93.

3. Roussos S, Fawcett SB. A review of collaborative partnerships as a strategy for improving community health. Annu Rev Public Health. 2000;21:369-402.

4. Provan KG, Milward HB. A preliminary theory of interorganizational network effectiveness: a comparative study of four community mental health systems. Adm Sci Q. 1995;40(1):1-33.

5. Shand F, Torok M, Cockayne N, Batterham PJ, Calear AL, Mackinnon A, et al. Protocol for a steppedwedge, cluster randomized controlled trial of the LifeSpan suicide prevention trial in four communities in New South Wales, Australia. Trials. 2020;21(1):332.

6. Black Dog Institute. Black Dog Institute Annual Report 2018-2019. Sydney: Black Dog Institute; 2020. Available from: https://www.blackdoginstitute.org.au/wp-content/uploads/2020/04/black-dogannual-report-2018-19.pdf.

7. Black Dog Institute. LifeSpan Trials. Black Dog Institute; 2020. Available from: https://www.blackdoginstitute.org.au/research-centres/lifespan-trials/.

8. Borgatti SP, Mehra A, Brass DJ, Labianca G. Network analysis in the social sciences. Science. 2009;323(5916):892-5.

9. Long JC, Bishop S. Social Network Research. In: Liamputtong P, editor. Handbook of Research Methods in Health Social Sciences. Singapore: Springer Singapore; 2018. p. 1-16.

10. Long JC, Cunningham FC, Carswell P, Braithwaite J. Who are the key players in a new translational research network? BMC Health Serv Res. 2013;13:338.

11. Long JC, Cunningham FC, Carswell P, Braithwaite J. Patterns of collaboration in complex networks: the example of a translational research network. BMC Health Serv Res. 2014;14(1):225.

12. Long JC, Cunningham FC, Wiley J, Carswell P, Braithwaite J. Leadership in complex networks: the importance of network position and strategic action in a translational cancer research network. Implement Sci. 2013;8:122.

13. Long JC, Hibbert P, Braithwaite J. Structuring successful collaboration: a longitudinal social network analysis of a translational research network. Implement Sci. 2016;11(19).

14. Long JC, Pomare C, Best S, Boughtwood T, North K, Ellis LA, et al. Building a knowledge exchange network in Australian clinical genomics: a social network study of the Australian Genomic Health 
Alliance. BMC Med. 2019;17(44).

15. Qualtrics. Qualtrics. Provo, Utah 2014. Available from: https://www.qualtrics.com/.

16. Borgatti SP, Everett MG, Freeman LC. UCInet for Windows: software for social network analysis. 6 ed. Harvard: Analytic Technologies; 2002.

17. Bastian M, Heymann S, Jacomy M. Gephi: an open source software for exploring and manipulating networks. International AAAI Conference on Weblogs and Social Media; 17-20 May; San Jose, California. 2009.

18. Damschroder LJ, Aron DC, Keith RE, Kirsh SR, Alexander JA, Lowery JC. Fostering implementation of health services research findings into practice: a consolidated framework for advancing implementation science. Implement Sci. 2009;4(1):50.

19. Harding J. Qualitative data analysis from start to finish. Northumbria University: Sage; 2013.

20. QSR International Pty Ltd. Nvivo Qualitatitve Data Analysis and Software. Version 12. 2018.

21. Saldana J. The coding manual for qualitative researchers. London: Sage; 2010.

22. Campbell J, Quincy C, Osserman J, Pedersen O. Coding in-depth semistructured interviews: problems of unitization and intercoder reliability and agreement. Sociol Methodol. 2013;42(3):294-320.

23. Tong A, Sainsbury P, Craig J. Consolidated criteria for reporting qualitative research (COREQ): a 32item checklist for interviews and focus groups. Int J Qual Health Care. 2007;19(6):349-57.

24. Pomare C, Churruca K, Long JC, Ellis LA, Braithwaite J. Organisational change in hospitals: a qualitative case-study of staff perspectives. BMC Health Serv Res. 2019;19(1):840.

25. Wilkins $\mathrm{CH}$. Effective Engagement Requires Trust and Being Trustworthy. Med Care. 2018;56 Suppl 10 Suppl 1(10 Suppl 1):S6-S8.

26. Knoben J, Oerlemans LAG. Proximity and inter-organizational collaboration: a literature review. Int J Manag Rev. 2006;8(2):71-89.

27. Costenbader E, Valente TW. The stability of centrality measures when networks are sampled. Soc Networks. 2003;25(4):283-307.

28. Pomare C, Long JC, Churruca K, Ellis LA, Braithwaite J. Social network research in health care settings: design and data collection. Soc Networks. 2019;[in press].

\section{Figures}




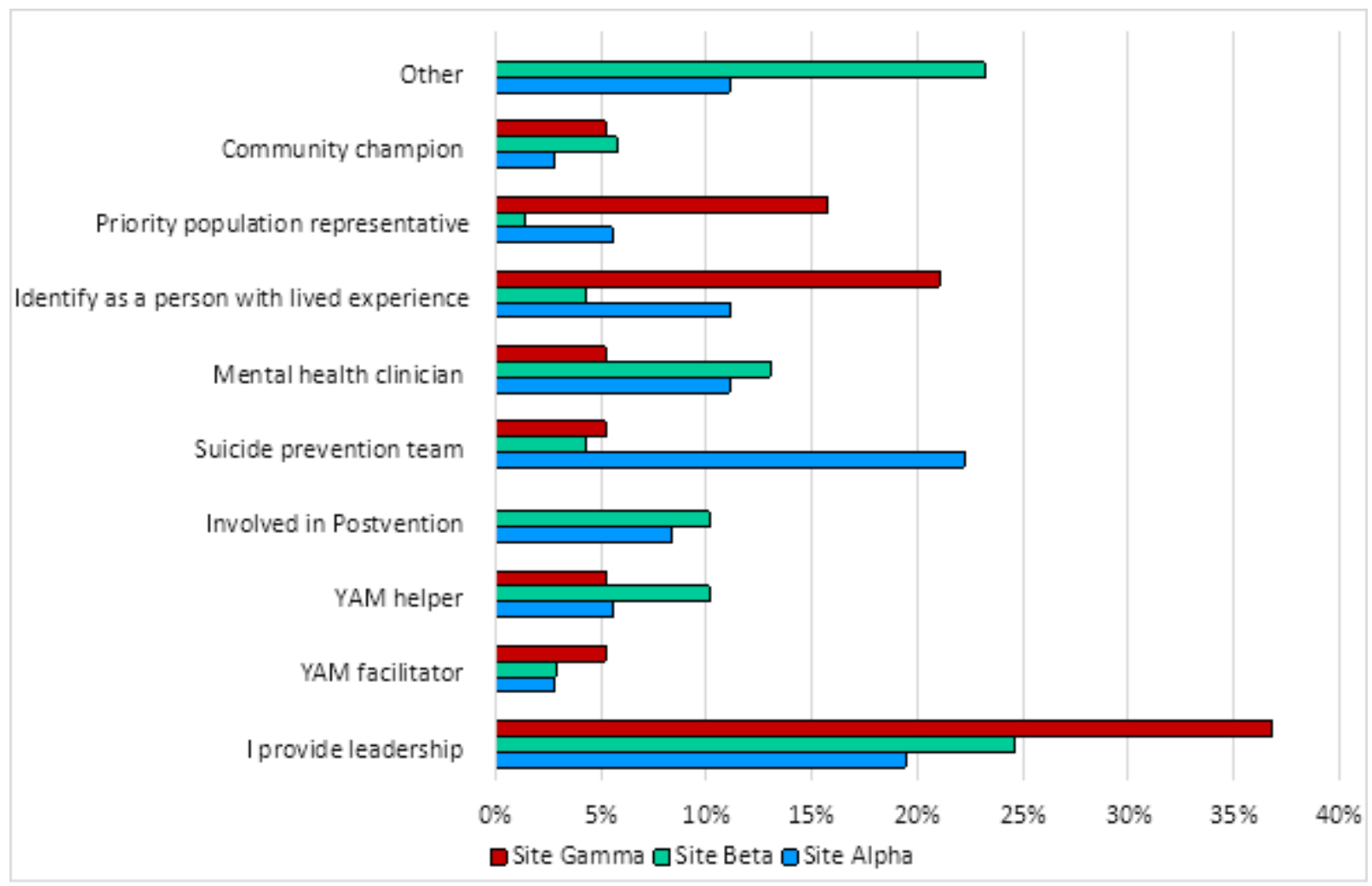

Figure 1

Percentage of respondents at each site nominating their role. Note respondents could select more than one role. (YAM = Youth Aware Mental Health)
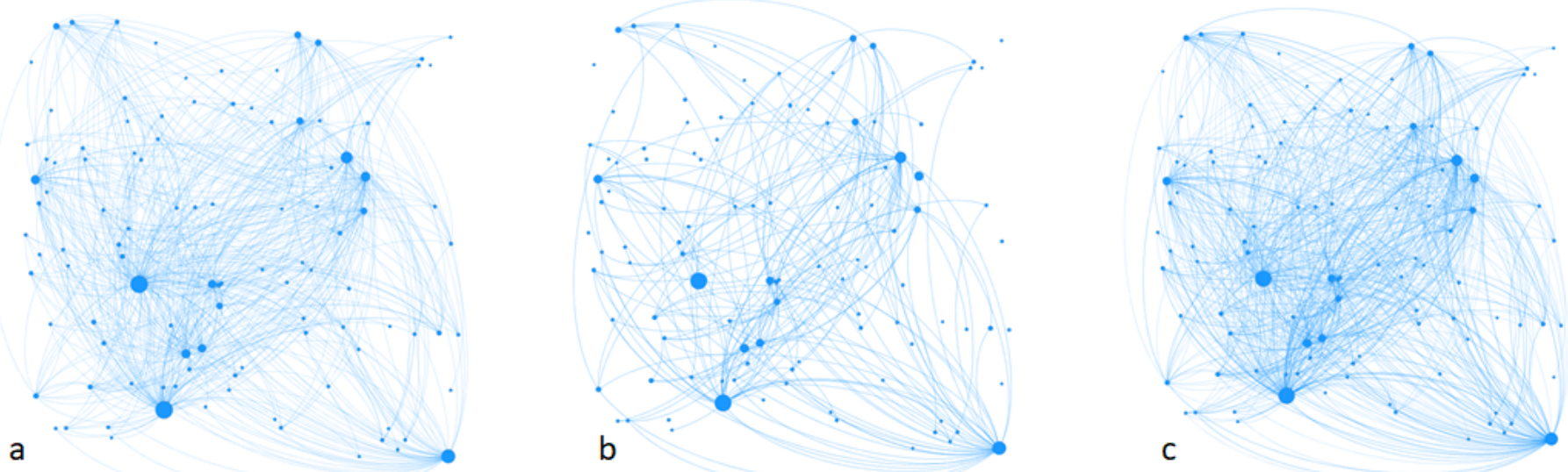

Figure 2

(a) Site Alpha existing ties, (b) Site Alpha new ties only, (c) Site Alpha all ties. Each node represents a person. Lines joining nodes indicates a relationship reported by the respondents. Size of the nodes indicates their relative importance in the network. 

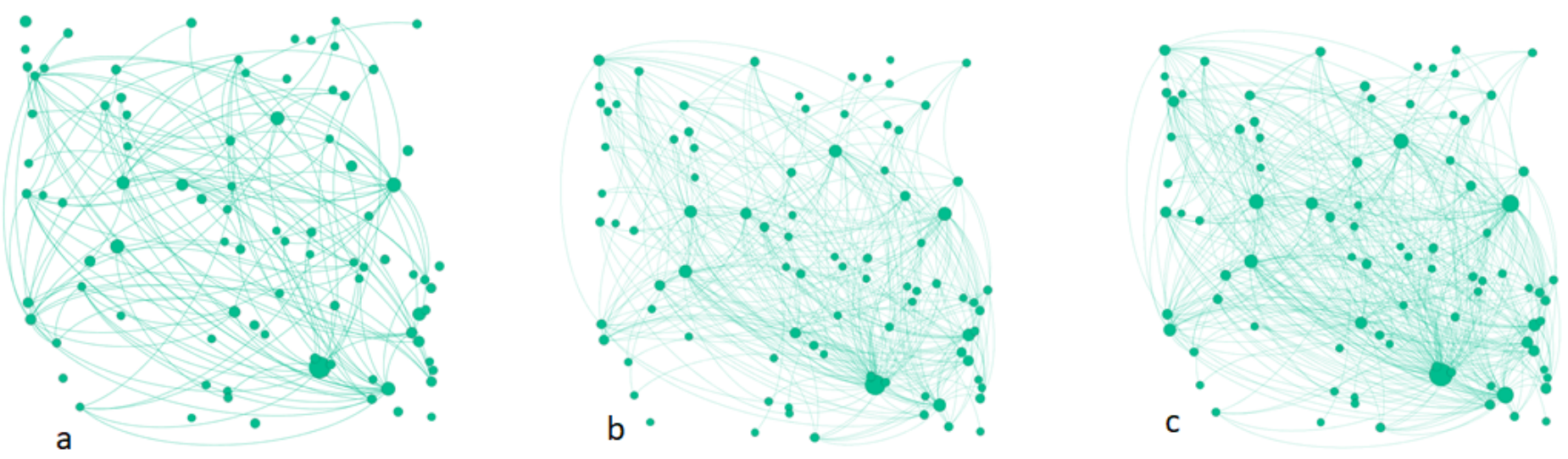

\section{Figure 3}

(a) Site Beta existing ties, (b) Site Beta new ties only, (c) Site Beta all ties. Each node represents a person. Lines joining nodes indicates a relationship reported by the respondents. Size of the nodes indicates their relative importance in the network.
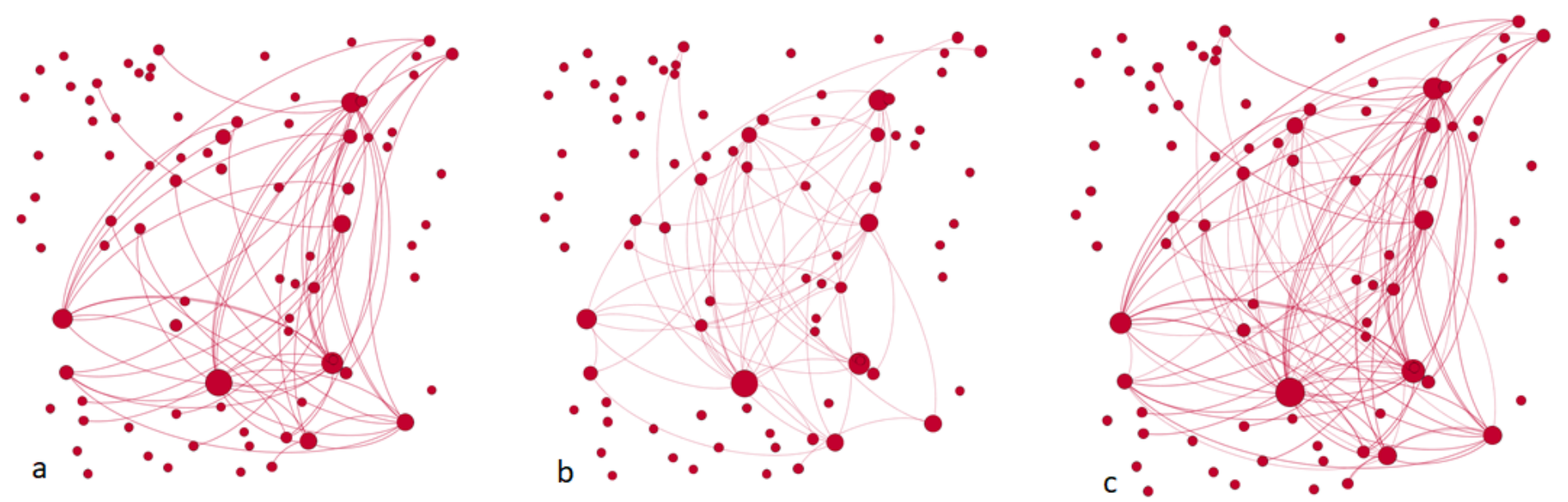

Figure 4

(a) Site Gamma existing ties, (b) Site Gamma new ties only, (c) Site Gamma all ties. Each node represents a person. Lines joining nodes indicates a relationship reported by the respondents. Size of the nodes indicates their relative importance in the network.

\section{Supplementary Files}

This is a list of supplementary files associated with this preprint. Click to download.

- SupplementaryFileA.docx

- SupplementaryFileBCOREQchecklist.docx 